\title{
The beliefs of mothers in southern Brazil regarding risk-factors associated with congenital abnormalities
}

\author{
Gilberto de Lima Garcias ${ }^{1}$ and Lavínia Schüler-Faccini ${ }^{2}$ \\ ${ }^{1}$ Universidade Católica de Pelotas and Universidade Federal de Pelotas, Pelotas, RS, Brazil. \\ ${ }^{2}$ Universidade Federal do Rio Grande do Sul, Departamento de Genética, Porto Alegre, RS, Brazil.
}

\begin{abstract}
We describes a study in which conventional wisdom about congenital malformations was investigated, the two main objectives being to list mothers' ideas by comparing six well-known causes of congenital abnormalities (ingestion of alcoholic beverages, smoking tobacco, drug use, marriage between relatives (consanguinity), rubella infection, maternal age) with explanations current in the general population and to discover the most common fallacies held by the general population concerning such abnormalities. The data were collected from 1 January to 31 December 1995 during a population study in which mothers were interviewed in hospitals in the city of Pelotas (population 400,000), Rio Grande do Sul state, Brazil. On each day of the study, the first three mothers to give birth were interviewed, resulting in 3,219 interviewed mothers out of 6,048 births. Our conclusion is that even though conventional wisdom is non-scientific it cannot be ignored because it is the source of a lot of suffering for the mother and can interfere with how she cares for her health. Although erroneous ideas about the causes of congenital abnormalities were more common among mothers from families receiving less than one minimum wage such ideas were found in all socioeconomic groups. In our discussion we emphasize that both mothers and the general public should be made aware of those risk-factors, especially maternal age and consanguinity, that really can cause congenital abnormalities.
\end{abstract}

Key words: congenital abnormalities, beliefs, superstition, pregnancy, teratogen.

Received: May 27, 2003; Accepted: December 4, 2003.

\section{Introduction}

The birth of a baby with congenital malformations and other abnormalities is probably one of the events in life which results in some of the strongest human emotions. Feelings of compassion, disgust, fear, guilt and curiosity are often expressed when this happens (Stevenson et al., 1993). In ancient times, children with congenital abnormalities were labeled "monsters" or as something extraordinary regarded as a prophetic sign because people believed they explained an existing (such as something the people were doing which displeased the gods) or predicted some future event. The development of natural sciences in Greece and the Hellenic world was not enough to stop people from believing in the prophetic meaning of congenital abnormalities, with ideas. about the predictive nature of congenital defects remaining important during all the Roman period. (Walton et al., 1993). Ambroise Paré begins his 1585 book Des Monstres (The Monsters) by writing that

Send correspondence to Gilberto de Lima Garcias. Universidade Católica de Pelotas and Universidade Federal de Pelotas, Pelotas, RS, Brazil. Av. Adolfo Fetter 1112, 96083-000 Pelotas, RS, Brazil. E-mail: garcias@phoenix.ucpel.tche.br.
"Monsters are things which do not follow the laws of Nature (for they usually mean some disgrace is about to happen (...) Prodigies are happenings totally against Nature)". Etymologically, the word "monster" comes from Latin monstrum (a portent, or a divine or evil omem indicating misfortune), akin to monstrare (to show, point out or indicate) and monere (to warn or remind) and these meanings should be kept in mind when we discuss people's past or present beliefs about congenital malformations and other congenital abnormalities.

Superstitions about congenital malformations have been with people from the dawn of time and are still very prevalent because these superstitions are seen as not merely abstract but also practical.. For example, although we are in the Twenty-first century, not the Middle Ages, millions of people still think of magic as their only option to fight illness and regain health (Inestrilas, 1992). Public-health studies should not ignore these alternative ways of interpreting the world because for several population groups they are the cause of real suffering in relation to health issues. Even when there is no scientific basis for such superstitions it must be realized that they are a future of many 
peoples reactions to anguish, stress, anxiety as well to the practical solutions they find for the uncertain and precarious situation which face them. Such beliefs result in health-related actions and reactions which need to be studied in detail in the context of public health (Castro, 1995).

The aim of the study described in this paper was to survey the population of the southern Brazilian city of Pelotas and identify the superstitions and beliefs related to congenital abnormalities. We discuss the ideas of mothers by comparing six well-known causes of congenital anomalies with explanations given by the population.

\section{Materials and Methods}

From 1 January to 31 December 1995 we surveyed post partum mothers in all the hospitals in the city of Pelotas (population 400,000), Rio Grande do Sul state, Brazil. The first three women to give birth one each day throughout the year were interviewed (3,219 interviewees out of 6,048 births) within $24 \mathrm{~h}$ of giving birth by trained interviewers and a questionnaire completed consisting of open and closed questions which included information about social, economic and demographic factors. Family income was calculated by summing the monthly incomes of the individual incomes within each family and expressing the total familiar income in terms of minimum wage (MW, about US\$80 as of January 2004. The mothers were grouped according to familiar income: less than 1 minimum wage (group 1); 1 to 3 minimum wages (group 2); 3.1 to 5 minimum wages (group 3); more than 5 minimum wages (group 4). Family income was used as a social and economic indicator because it is easily measured despite the complexity of different social classes Victora et al. (1989) having shown a strong association between social class and family income and demonstrated that this relationship can be used to indicate social class. It should be noted that a family receiving one or less minimum wages would be considered very poor.

The first part of the questionnaire had several questions to assess how much the mothers knew about six risk-factors (ingestion of alcoholic beverages, smoking tobacco, drug use (both prescription and illicit), marriage among relatives (consanguinity), rubella infection, maternal age) which the current scientific literature indicates as causes of congenital abnormalities. In addition to asking if they thought than these risk-factors could be a problem to the child we also asked what these problems might be.

The second part of the questionnaire had open questions which allowed mothers to express their opinion on congenital malformations and their causes, the mothers responses being divided into three categories: reasonable (agreeing with scientific evidence; category 1); possible (no scientific confirmation for the belief, but it cannot be ruled out as a possibility; category 2); and unreasonable (beliefs with no scientific basis; category 3 ). We considered category 3 responses to be the most important because al- though the responses may have been logical the beliefs expressed in them would not lead to behavioral modifications which would prevent congenital abnormalities.

The ratio of the prevalence of beliefs in the different income-groups of was assessed using a confidence interval of $95 \%$. The base income-groups was the one presumed to have the highest level of education (i.e. with a monthly family income of more than 5 minimum wages), the assumed prevalence ratio for this category being 1.0. Differences between categories were measured using the Chisquared at the $5 \%$ significance level. To create our database and analyze our results statistically we used Version 6.02 of the Epi Info program (Dean et al., 1994).

\section{Results}

The mothers' opinions concerning the effect of riskfactors on congenital malformations are shown in Table 1, presented in the order in which the questions were asked in the questionnaire. Smoking and alcohol consumption were the most accepted risk-factors and maternal age the least accepted risk-factor. Regarding socioeconomic level based on monthly family income, only $175(5.4 \%)$ mothers out of 3,219 interviewed had an income of less than one minimum wage. The largest group contained 1,906 mothers (59.2\%) receiving between 1 and 3 minimum wages, while 582 mothers (18\%) received between 3.1 and 5 minimum wages and 556 mothers $(17.8 \%)$ more than 5 minimum wages (our reference group), almost equal to the 3.1 to 5 minimum wage group. In Tables 2 to 4 the significant differences shown are as compared to the $>5$ minimum wage socioeconomic group (group 4).

Two of the three risk-factors most cited in the scientific literature for their role in congenital anomalies are consanguinity between parents and maternal age, Table 2 showing that, as compared to group 4 mothers, significantly less mothers in the lowest socioeconomic group (group 1) viewed consanguinity as a risk-factor while significantly more group 1 mothers than group 4 mothers thought that maternal age was a risk factor. We also found that $64 \%$ of all the mothers sampled (groups 1 to 4 , inclusive) thought that there was some connection between con-

Table 1 - Mothers' beliefs concerning the association between congenital defects and risk-factors.

\begin{tabular}{lccc}
\hline \multirow{2}{*}{ Risk-factor } & \multicolumn{3}{c}{ Beliefs about cause-effect relationship } \\
\cline { 2 - 4 } & Yes (\%) & No (\%) & Don’t know (\%) \\
\hline Smoking tobacco & 88.4 & 7.2 & 4.4 \\
Alcohol consumption & 88.8 & 4.4 & 6.8 \\
Drug use & 83.6 & 9.9 & 6.5 \\
Rubella & 65.6 & 5.4 & 29.0 \\
Consanguinity & 64.1 & 23.8 & 12.1 \\
Maternal age & 42.3 & 51.0 & 6.7 \\
\hline
\end{tabular}


Table 2 - Mothers' beliefs concerning consanguinity between parents and maternal age as risk-factors for congenital defects.

\begin{tabular}{|c|c|c|c|c|c|c|c|c|c|c|}
\hline \multirow{2}{*}{\multicolumn{3}{|c|}{ Family income }} & \multicolumn{8}{|c|}{ Risk-factor } \\
\hline & & & \multicolumn{4}{|c|}{ Consanguinity between parents } & \multicolumn{4}{|c|}{ Maternal age } \\
\hline MS & $\mathrm{n}$ & $\%$ (column) & Positive & $\%$ (row) & PR & $95 \% \mathrm{CI}$ & Positive & $\%$ (row) & PR & $95 \%$ CI \\
\hline$<1$ & 175 & 5.5 & 104 & 59.4 & $0.75^{*}$ & $(0.66-0.85)$ & 85 & 48.6 & $1.52 *$ & $(1.25-1.84)$ \\
\hline $1-3$ & 1,906 & 59.2 & 1,143 & 60.0 & $0.76^{*}$ & $(0.76-0.81)$ & 892 & 46.8 & $1.46^{*}$ & $(1.28-1.67)$ \\
\hline $3.1-5$ & 582 & 18.1 & 382 & 65.8 & $0.84 *$ & $(0.77-0.90)$ & 206 & 35.4 & $1.11^{\mathrm{ns}}$ & $(0.94-1.30)$ \\
\hline$>5$ & 556 & 17.2 & 435 & 78.2 & 1.0 & & 178 & 32.0 & 1.0 & \\
\hline Total & 3,219 & & 2,064 & 64.1 & & & 1,361 & $42.3 \%$ & & \\
\hline
\end{tabular}

Key: MS = number of minimum salaries per month; $n=$ number of mothers in each income group; Positive = number of mothers agreeing that the risk-factor heading the column could cause congenital malformations; $\mathrm{PR}=$ Prevalence ratio; $\mathrm{CI}=\mathrm{Confidence}$ interval; $\mathrm{ns}=$ non significant. $*$ Significantly different at the $5 \%$ level as compared to the $>5$ minimum wage socioeconomic group. Percentage for column $=\mathrm{n} / \mathrm{Total}(\Gamma \mathrm{n}) \mathrm{x} 100$; for rows $=$ positive/ $\mathrm{n}$ for that row $\mathrm{x} 100$.

Table 3 - Mothers' beliefs concerning rubella infection and drug use during pregnancy as risk-factors for congenital abnormalities.

\begin{tabular}{|c|c|c|c|c|c|c|c|c|c|c|}
\hline \multirow{2}{*}{\multicolumn{3}{|c|}{ Family income }} & \multicolumn{8}{|c|}{ Risk-factor } \\
\hline & & & \multicolumn{4}{|c|}{ Rubella infection } & \multicolumn{4}{|c|}{ Drug use during pregnancy } \\
\hline MS & $\mathrm{n}$ & $\%$ (column) & Positive & $\%$ (row) & PR & $95 \% \mathrm{CI}$ & Positive & $\%$ (row) & PR & $95 \% \mathrm{CI}$ \\
\hline$<1$ & 175 & 5.4 & 95 & 54.3 & $0.64 *$ & $(0.55-0.73)$ & 140 & 80.0 & $0.87 *$ & $(0.80-0.94)$ \\
\hline $1-3$ & 1906 & 59.2 & 1138 & 59.7 & $0.70 *$ & $(0.66-0.73)$ & 1549 & 81.3 & $0.91 *$ & $(0.89-0.94)$ \\
\hline $3.1-5$ & 582 & 18.0 & 404 & 69.4 & $0.81 *$ & $(0.76-0.87)$ & 489 & 84.0 & $0.91^{*}$ & $(0.87-0.95)$ \\
\hline$>5$ & 556 & 17.8 & 475 & 85.5 & 1.0 & & 514 & 92.4 & 1.0 & \\
\hline Total & 3,219 & & 2,112 & 65.6 & & & 2,692 & 83.6 & & \\
\hline
\end{tabular}

Key: MS = number of minimum salaries; $\mathrm{n}=$ number of mothers in each income group; Positive = number of mothers agreeing that the risk-factor heading the column could cause congenital malformations; $\mathrm{PR}=$ Prevalence ratio; $\mathrm{CI}=$ Confidence interval. $*$ Significantly different at the $5 \%$ level as compared to the $>5$ minimum wage socioeconomic group. Percentage for column $=\mathrm{n} /$ Total $(\Gamma \mathrm{n}) \times 100$; for rows $=$ positive $/ \mathrm{n}$ for that row $\mathrm{x} 100$.

Table 4 - Mothers' beliefs concerning smoking tobacco and alcohol consumption as risk-factors for congenital abnormalities.

\begin{tabular}{|c|c|c|c|c|c|c|c|c|c|c|}
\hline \multirow{2}{*}{\multicolumn{3}{|c|}{ Family income }} & \multicolumn{8}{|c|}{ Risk-factor } \\
\hline & & & \multicolumn{4}{|c|}{ Smoking tobacco } & \multicolumn{4}{|c|}{ Alcohol consumption } \\
\hline MS & $\mathrm{n}$ & $\%($ column $)$ & Positive & $\%$ (row) & PR & $95 \% \mathrm{CI}$ & Positive & $\%$ (row) & PR & $95 \% \mathrm{CI}$ \\
\hline$<1$ & 175 & 5.4 & 149 & 85.2 & $0.90 *$ & $(0.84-0.96)$ & 152 & 87.0 & $0.93 *$ & $(0.87-0.99)$ \\
\hline $1-3$ & 1906 & 59.2 & 1643 & 86.2 & $0.91 *$ & $(0.88-0.93)$ & 1658 & 87.0 & $0.93 *$ & $(0.93-0.96)$ \\
\hline $3.1-5$ & 582 & 18.0 & 525 & 90.2 & $0.95 *$ & $(0.92-0.98)$ & 530 & 91.0 & $0.97^{\mathrm{ns}}$ & $(0.94-1.01)$ \\
\hline$>5$ & 556 & 17.8 & 528 & 95.0 & 1.0 & & 520 & 93.5 & 1.0 & \\
\hline Total & 3,219 & & 2,845 & 88.4 & & & 2,860 & 88.8 & & \\
\hline
\end{tabular}

Key: $\mathrm{MS}=$ number of minimum salaries; $\mathrm{n}=$ number of mothers in each income group; Positive = number of mothers agreeing that the risk-factor heading the column could cause congenital malformations $\mathrm{PR}=$ Prevalence ratio; $\mathrm{CI}=$ Confidence interval; ns $=$ non significant. * Significantly different at the $5 \%$ level as compared to the $>5$ minimum wage socioeconomic group. Percentage for that row x 100 .

sanguinity and congenital abnormalities, $30.5 \%$ of which connected consanguinity with multiple malformations, $17 . \%$ with mental retardation and the rest with several less severe congenital problems. A lower percentage (42\%) of all the mothers sampled stated that maternal age was an important risk-factor. Beliefs regarding maternal age as a risk-factor was the only case we found of an inverse rela- tionship between social class and 'correct scientific knowledge', with $48 \%$ of group 1 mothers (the poorest group) stating that maternal age can increase the probability of congenital abnormalities but only $32 \%$ of group 4 mothers (the wealthiest) holding the same opinion. Of the mothers who stated that maternal age was a risk-factor, 9.5\% declared that it could lead to multiple abnormalities, $6.7 \%$ that 
it could cause abortion and $5.9 \%$ that it was the cause of Downs Syndrome.

Both rubella and the use of drugs can be important sole factors in the genesis of congenital abnormalities, the mothers' opinions about these risk-factors being shown in Table 3. Both these risk-factors were underestimated by low-income group 1 mothers. About $65 \%$ of all the mothers sampled stated that rubella could cause congenital abnormalities in the fetus if the mother was exposed to the virus during pregnancy, with $14 \%$ of this percentage declaring that it could cause multiple malformations, $10.9 \%$ abortion, $7.4 \%$ facial abnormalities, $4.5 \%$ rubella infection and $4.1 \%$ deafness. Almost $84 \%$ of all the mothers sampled stated that the use of drugs during pregnancy could cause congenital abnormalities and there was a high incidence of this belief in all social classes. Even so, only about half the mothers stated that congenital abnormalities can occur if drugs are used during the first trimester of pregnancy, indicating that half of the mothers surveyed did not know which period of pregnancy represented the greatest risks. Drug use during pregnancy was considered a risk factor which can lead to abortion by $14.9 \%$ of all the mothers sampled, with $13.9 \%$ citing multiple malformations and $8.3 \%$ mental retardation.

Mothers' opinions on smoking tobacco and alcohol consumption during pregnancy are given in Table 4. Even though these are well known factors which can lead to problems during pregnancy and congenital abnormalities our sample of mothers did not consider these factors as important as the other risk-factors, although they were the ones most commonly associated by mothers with congenital abnormalities. Smoking tobacco was stated a risk-factor for congenital abnormalities by about $88,4 \%$ of mothers, with $58 \%$ of this percentage declaring that smoking can cause abnormalities in the child's respiratory system, 7.7\% that it can cause general weakness and $2.2 \%$ that it could be a cause of mental retardation. None of the mothers associated smoking with decreased birth weight which is commonly cited in the scientific literature as one of the principle effects of smoking tobacco. Alcohol consumption during pregnancy was stated to be a problem by about $88,8 \%$ of the mothers, $18.7 \%$ of this percentage associating alcohol consumption with mental retardation, 5.3\% with addiction by the mother or child, $4.4 \%$ with retarded development of the child and $4 \%$ with multiple malformations.

The responses to our questionnaire show that the mothers sampled have many different views on congenital abnormalities and show a great deal of creativity in trying to explain the unknown. In the 3219 interviews which we carried out there were 1191 causes for congenital abnormalities that could be classified either as beliefs, myths or superstitions. It appears that such ideas were independent of social class, with $27 \%$ of mothers in the highest social class (group 4, >5 MW) and $41 \%$ of mothers in the second highest social class (group 3, 3.1 - $5 \mathrm{MW}$ ) holding such views. One third of the mothers interviewed mentioned some fantastic or absurd cause as a reason for congenital abnormalities. The most frequently mentioned reasons were wearing items such as necklaces, bracelets or keys $(51.6 \%)$, crossing under a wire fence or walking under a ladder (19.9\%) and spilling liquids on the belly or touching it with objects $(13,8 \%)$. The single most common idea mentioned by the mothers was that carrying a key attached to the body can cause congenital anomalies, $71 \%$ of mothers (2285) having heard about this, with $34 \%$ associating this with facial anomalies (especially cleft-lip) and $34.7 \%$ with skin abnormalities.

Explanations accepted by the general population as to the causes of congenital anomalies appear to be linked to specific cause-effect actions, a rational which is simple, gives an immediate explanation and is apparently appropriate because the action resembles the type of congenital abnormality or childbirth problem. The cause-effect associations given by the mothers sampled are presented in Table 4.

\section{Discussion}

Risks to the fetus caused by maternal exposure to specific risk-factors can be decreased if the mother is aware of such factors because such knowledge lead to preventive behavior. It is, therefore, important that mothers accept that congenital abnormalities can occur and adopt effective measures to avoid them, although the road to such measures, which should be taken by every couple who wants to have a baby, is usually filled with uncertainties.

The mothers' responses to the first step, being aware of the risk-factors (which we term 'preventive behavior'), could be divided into two distinct population groups, one formed by the more vulnerable low-income group 1 mothers and the other by mothers in socioeconomic groups 2-4 who come from higher-income families and who have more education and are therefore less likely to have a child with congenital abnormalities. These findings support the opinion of Castilla et al. (1996) who wrote that '...as far as congenital abnormalities are concerned, a realistic strategy should concentrate on actions of primary prevention (preconception) in the poorer social classes, secondary prevention (pre-natal) in the richer classes; and tertiary prevention (post-natal) in both'. Of the six risk-factors presented to the mothers, five (consanguinity, rubella, drug use; smoking and alcohol consumption) were more easily identified by mothers in family-income groups 2-4 than by those in group 1, the lowest family-income group. The exception was maternal age, which was considered to be a risk factor by only one third of all the mothers, even though this is one of the most important risk-factors in Brazilian society (Castilla et al., 1996; Gusmão et al., 2003).

The age at which a woman has her first baby is intimately related to the kind of work she has, which also seems to be associated with professional emancipation. 
This may explain why women in the wealthier socioeconomic groups tend to leave motherhood until they achieve better social and economic conditions and trade good reproductive age for better social conditions. The risk-factors for congenital abnormalities which were most commonly mentioned by the mothers surveyed by us were those associated with lifestyle, such as smoking tobacco and ingestion of alcohol or drugs. Despite the existence of studies linking smoking tobacco to congenital malformations (Ericson et al., 1979; Czeizel et al., 1994; Rooij et al., 2001), we know that this is probably the least important risk-factor compared to the others investigated in our survey. The large number of women who mentioned smoking as a risk-factor is probably due to advertising campaigns by the Brazilian Health Ministry warning about the risks to the baby's health of cigarette smoking.

Even though a high percentage $(84 \%)$ of the mothers surveyed stated that taking drugs during pregnancy is bad for the fetus, $76.7 \%$ of them reported taking some kind of medicine during pregnancy; indicating that awareness of a risk-factor does not necessarily lead to effective prevention. Associations between maternal drug use and infant cardiovascular defects have been identified for many different medications (Kallen and Otterblad, 2003). Another study on the connection between pre-natal orientation regarding the effects of smoking, alcohol and drug use during pregnancy and the use of these drugs by expectant mothers concluded that drugs are used anyway, despite pre-natal instruction, level of education, maternal age, or the developmental level of the country (Zullini et al., 1998).

Rubella is the infection which is most teratogenic during pregnancy (Castillo-Solorzano et al., 2003), but in our study one-third of women stated either that that there was no association between rubella and fetal abnormalities or that they did not know of such an association. This figure is alarming because of the lack of knowledge which it indicates, the small number of vaccinations and the risk of infection which women face during their fertile years.

Incestuous relationships had already been banned by the Pentateuch (the first five books of the Old Testament), the Koran and several catholic councils when science confirmed that consanguinity increases the frequency of recessive abnormalities in the population. In our study, the overall percentage of mothers stating that there were possible risks for the newborn if the parents were related was only $64 \%$, although this varied according to socioeconomic group with the percentage increasing as family income increased. This data shows that there is an urgent need for educating the public on the deleterious effects of inbreeding, especially in developing countries with high overall consanguinity rates and limited financial resources (Nabulsi et al., 2003).

In our survey the mothers' perception of the riskfactors studied was inversely related to their real importance, with the most important risk-factor in terms of the overall percentage of mothers mentioning it being smoking and the least important maternal age. This is surprising because previous studies carried out in Brazil (Schilmoeller and Baranowski, 1985; Stickle, 1981) have show exactly the opposite, although in our case the fact that the Brazilian government has recently invested in large-scale media campaigns, directed at not only the general public but also pregnant women, on the potential risks of smoking and drinking while information about maternal age as a riskfactor is generally restricted to health clinics or other specialized health services. Anthropologists have reported major differences between distinctive cultural groups in relation to fertilization, pregnancy and labor. Hahn and Muecke (1987) call this system of inherited beliefs 'birth culture', and according to them this culture '...informs the members of the society about the nature of fertilization, the appropriate conditions for reproduction and pregnancy, the way pregnancy and labor work, and the rules and logical fundamentals of behavior before and after birth'. According to Del Priore (1989) mothers can be seen as a 'womantree', fertile and in constant mimicry of nature, and are owners of a womb where offspring are conceived and who can also offer that same womb for the gestation of monsters with, consequently, motherhood in modern times hanging between the light of perfect beings and the darkness of those who are not. The existence of this duality in women can lead to the birth of 'angels' or 'demons' and means that society needs to create explanations which lead to all sorts of beliefs about the causes of the birth of an imperfect child. Jahoda (1977) writes that '...in situations of great danger and anxiety or of great uncertainty, superstitions are very likely to exist', which might explain why over a third of the mothers interviewed by us had bizarre explanations for congenital abnormalities or birth problems which are certainly examples of dangerous and uncertain situations.

When we analyzed the explanations and associations between the cause and effect of congenital abnormalities we tried to find the logic behind the beliefs. Every culture has its own beliefs about the vulnerability of the mother and the fetus during pregnancy, with culture-related ideas about the anatomy and physiology of the mother-fetus often being invoked after the birth of a child to explain post hoc any unwanted result, such as a retarded, deformed or sick child (Helman, 1994). In our study we found a large number of statements which confirm the idea that the mother and child are regarded as a single entity, with associations being made between spilling liquids on the mothers' body and birthmarks on the baby, the mother carrying keys and cleft lip in the baby, the mother wearing sunglasses and blindness in the baby, unfulfilled wishes of the mother to eat something and various abnormalities in the baby. The idea that the mothers' unfulfilled wishes can 'mark' a child forever has been shown to occur in several countries, including England (Snow and Johnson, 1978), India (Homans, 1982) and Latin America (Castro, 1995). 
When parents are informed about the existence of a congenital defect this becomes a tragedy that can jeopardize their plans, self-esteem and identity. The importance of a woman is magnified during pregnancy but so is her responsibility for the fate of this baby, with phrases like 'Don't cry because you may hurt the baby' acquiring a new meaning and clearly implying that the woman can be held responsible in the event of a negative outcome. There is also the belief that the mothers' thoughts and feelings can affect the child, which means that, due to the universal ambivalence of feelings about babies, in the event of an abnormality the mother will blame herself for those moments of

Table 5 - Cause-effect associations for congenital abnormalities as given by the mothers sampled.

\section{Birthmarks such as nevi and hemangiomas}

Spilling drinks such as wine or soft drinks over the belly; wearing creams or sun protectors; making drawings on the skin; carrying a tree leaf attached to the body. It appears that these belief are based on the idea that anything which touches the belly can be transferred to the child.

Facial abnormalities such as cleft-lip or malformations of the ear and nose

Wearing keys attached to the body, piercing the ears; carrying metal objects in the bra; holding a needle between the lips while sewing; carrying tokens or coins; wearing necklaces and earrings.

\section{Birth of normal or conjoined twins}

Eating 'twined' fruit (i.e. fruits that are stuck together) or having too much sex.

\section{Umbilical cord problems such as twists or knots}

Passing underneath wire fences; moving over the husband in bed (or the husband moving over the mother); walking under ladders; going through narrow doors or gates.

Limb abnormalities such as ectrodactyly and syndactyly Eating the legs of animals (especially chicken and pork) during pregnancy.

\section{Blindness}

The mother wearing sunglasses or closing her eyes while having her picture taken while pregnant.

\section{Sexual problems with the child}

The mother being sexually abused, watching pornographic movies, reading pornographic magazines or thinking about pornography

\section{Abortion or stillborn baby}

Getting the baby's room ready or buying the crib before birth; expecting the baby with too much anxiety.

\section{Attitudes and behavior that can lead to non-specific prob-} lems

Looking at, laughing at or imitating people with congenital abnormalities; looking at ugly people; going to funerals; walking near cemeteries; rejecting the pregnancy; cursing; getting married while pregnant; going to weddings; feeding, walking or killing animals; committing a sinful act; eating ice or the skin of a fruit; sitting on the table; wearing safety pins; having a wish to eat something and not doing so; thinking about children with congenital abnormalities; talking about diseases or watching movies about sick children negative feelings and ideas (Defey, 1996). This fact, in association with the divine status that has always been attributed to the uncommon being, can turn the baby into an agent of God's punishment. The mothers' responses shown in Table 5 indicate several situations that point to guiltpunishment as the rational for explaining some congenital abnormalities, e.g. having sinned, looking or laughing at abnormal people, rejecting the pregnancy, cursing, getting married while pregnant and pornography-related activities.

Anthropologists affirm that not every taboo and restriction concerning pregnancy constitutes a protective element against physical damage for the mother and child: a pregnant woman is indeed in a state of social vulnerability and ambiguity. She is in a state of transition between two social roles - mother and wife. While in this borderline state, just as in other cases of social transition, the woman involved is seen as if she were in an ambiguous and 'abnormal' state which is dangerous both for herself and the people around her. Therefore, the rituals and taboos associated with pregnancy act both as markers of this transition and as protection for the mother and fetus during this dangerous period (Homans, 1982).

Although conventional wisdom is non-scientific it cannot be dismissed because it is the source of much suffering for the mother and is related to her health. In spite of the fact that erroneous ideas as to the causes of congenital abnormalities were more common in the less wealthy socioeconomic groups we also found such concepts in the wealthier socioeconomic groups, and it is important that those factors that are real risk-factors in congenital abnormalities, especially maternal age and consanguinity, are brought to the attention of both mothers and the general population.

\section{Acknowledgments}

This work was funded by the Brazilian Research Council (CNPq) and by the Brazilian Ministry of Education (CAPES).

\section{References}

Castilla EE, Lopez-Camelo JS, Paz JE and Orioli IM (1996) Prevención Primaria de los Defectos Congénitos. Editora FIOCRUZ, Rio de Janeiro.

Castillo-Solorzano C, Carrasco P, Tambini G, Reef S, Brana M and de Quadros CA (2003) New horizons in the control of rubella and prevention of congenital rubella syndrome in the Americas. J Infect Dis 15:187 Suppl.

Castro R (1995) La lógica de una de las creencias tradicionales en salud: Eclipse y embarazo en Ocuituco, México. Salud Públ México 37(4):329-338.

Czeizel AE, Kodaj I and Lens W (1994) Smoking during pregnancy and congenital limb deficiency. Brit Med J 308:1473-1476.

Dean AG, Dean JA, Coulombier D, Brendel, KA, Smith DC, Burton AH, Dicker RC, Sullivenn K, Fagan RF and Arner TG (1994) Epi info, Version 6: A Word Processing, Database, 
and statistics Program for Epidemiology on Microcomputers. Atlanta: Centers for Disease Control and Prevention.

Defey D (1996) Los bebés y sus padres en situaciones difíciles. Serie Mujer y Maternidad, Tomo IV. Roca Editorial, Montevideo.

Del Priore M (1989) A Maternidade da Mulher Negra no Período Colonial Brasileiro. São Paulo, Estudos CEDHAL 4.

Ericson A, Källen B and Westerholm P (1979) Cigarette smoking an etiologic factor in cleft lip and palate. Am J Obstet Gynecol 135:348-351.

Gusmão FAF, Tavares EJM and Moreira LMA (2003) Idade materna e síndrome de Down no Nordeste do Brasil. Cad Saúde Pública 19(4):973-978.

Hahn RA and Muecke MA (1987)The anthropology of birth in five US ethnic populations: implications for obstetrical practice. Current Probl Obstet Gynecol Fert 10:133-171.

Helman CG (1994) Cultura, Saúde e Doença. Artes Médicas, Porto Alegre.

Homans H (1982) Pregnancy and birth as rites of passage for two groups of women in Britain. In: MacCormack CP (ed) Ethnography of Fertility and Birth. Academic Press, London.

Inestrilas JA (1992) IV La Mandrágora: Planta de magia e razón. In Panaceas y talismanes. Gaceta Med Mexico 128(2):176177.

Jahoda G (1977) Psicologia da Superstição. $2^{\mathrm{a}}$ ed. Paz e Terra, São Paulo.

Kallen BA and Otterblad OP (2003) Maternal drug use in early pregnancy and infant cardiovascular defect. Reprod Toxicol 17(3):255-261.

Nabulsi MM, Tamim H, Sabbagh M, Obeid MY, Yunes KA and Bitar FF (2003) Parental consanguinity and congenital heart malformations in a developing country. Am J Med Genet 116 A(4):342-347.

Paré A (1585) Monstruos y Prodigios. Ediciones Siruela, Madrid.

Rooij IALM, Wegerif MJM, Roelofs HMJ, Peters WHM, Kuijpers-Jagtman AM, Zielhuis GA, Merkus HMWM and Steegers-Theunissen RPM (2001) Smoking, genetic polymorphisms in biotransformation enzymes, and nonsyndromic oral clefting: A gene-environment interaction. Epidemiology 12:502-507.

Schilmoeller GL and Baranowski M (1985) Childrearing of firstborns by adolescents and older mothers. Adolescence 20(80):805-822.

Snow LF and Johnson SM (1978) Folklore, food, female reproductive cycle. Ecol Food Nut 7:41-49.

Stevenson RE, Hall JH and Goodman RM (1993) Human malformation and related Anomalies. v. 1. Oxford Monographs on Medical genetics n. 27. Oxford University Press, New York.

Sticlke G (1981) Overview of incidence, risks and consequences of adolescents pregnancy and childbearing. Birth Defects original article series 17(3):5-17.

Victora CG, Barros FC and Vaughan JP (1989) Epidemiologia da Desigualdade. $2^{\mathrm{a}}$ ed. Ed. HUCITEC, São Paulo.

Walton MT, Fineman RM and Walton PJ (1993) Of monsters and prodigies: The interpretation of birth defects in the sixteenth century. Am J Med Genet 47:7-13.

Zullini Da Costa MT, Quintal VS, Haro FMB, Picchi M, Salgado, MVS, Okay Y, Ramos JLA and Vaz FAC (1998) Drogas de abuso na gestação: As orientações no pré-natal são suficientes? Pediatria 20(4):316-320.

Editor Associado: Francisco Mauro Salzano 